2. To: (Receiving Organization)

GJ Gauck, SST Engineering

\section{Proj./Prog./Dept./Div.:}

SST Engineering

3. From: (Originating Organization)

AM Ermi, COGEMA Engineering

6. Design Authority/Design Agent/Cog. Engr.:

GJ Gauck

\section{Originator Remarks:}

Acceptance Test Plan for the new DACS [INSTPROB] screen, per DACS Change Control Board System Change Request \#448. The ATP will be performed in the $306 \mathrm{E}$ DACS Development Laboratory prior to installation of DACS V. 4.02 software in the DACS Trailer.
11. Receiver Remarks:
11A. Design Baseline Document? $\bigcirc$ Yes $O$ No

4. Related EDT No:

$\mathrm{N} / \mathrm{A}$

7. Purchase Order No:

$\mathrm{N} / \mathrm{A}$

9. Equip./Component No.:

$\mathrm{N} / \mathrm{A}$

10. System/Bldg./Facility:

12. Major Assm. Dwg. No.:

$\mathrm{N} / \mathrm{A}$

13. Permit/Permit Application No.:

14. Required Response Date:

June 24,1999

15.

\begin{tabular}{|l|l|}
\hline $\begin{array}{c}\text { (A) } \\
\text { tiem } \\
\text { No. }\end{array}$ & (B) Document/Drawing No. \\
\hline 1 & HNF -4687 \\
\hline & \\
\hline & \\
\hline & \\
\hline & \\
\hline & \\
\hline & \\
\hline
\end{tabular}

16.

Approval Designator $(\mathbf{F})$

$E, S, Q, D O R N / A$

(See WHC-CM-3-5, Sec. 12.7)

17.

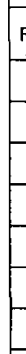

1 Env.
DATA TRANSMITTED

\begin{tabular}{ll|l} 
(C) Sheet & (D) Rev. & (E) Titte or Description of Data Transmitted \\
No. &
\end{tabular}
(F)

(G)

Approval Reason Origi- Receiv-

Desig- for Trans- nator er

nator mittal Dispo- Dispo-

11 Design Authority RE Larson $R=\ln 6 / 22 / q_{T 4-07}$

11 Design Agent AM Errmi am Emi c/17/1916-37

1 I Cog. Eng. Gu Gauck \& A kem L6/1/79.T4-07

11 Cog. Mgr. RE Larson REfmea $6 /$ es/99T4-07

$1 \quad 1$ QA RR True PRPene 6-21-99-07

11 safety Ls krogsrud $/ 8 / \mathrm{Ku}^{6 / 22 / 99} \mathrm{~T} 4-07$

Amfini 6/17/99

AM Ermi

Signature of EDT

Originator
Reason for Transmittal (G)

4. Review

6. Dist. (Receipt Acknow. Required)

SIGNATURE/DISTRIBUTION

(See Approval Designator for required signatures)

KEY

TP

\begin{tabular}{l|l|l|}
$S Q$ & 1 & 1 \\
\hline
\end{tabular}

Disposition $(\mathrm{H})$ \& (I)

1. Approved

2. Approved w/comment

Disapproved wicomment
4. Reviewed no/comment

5. Reviewed w/comment

6. Receipt acknowledged

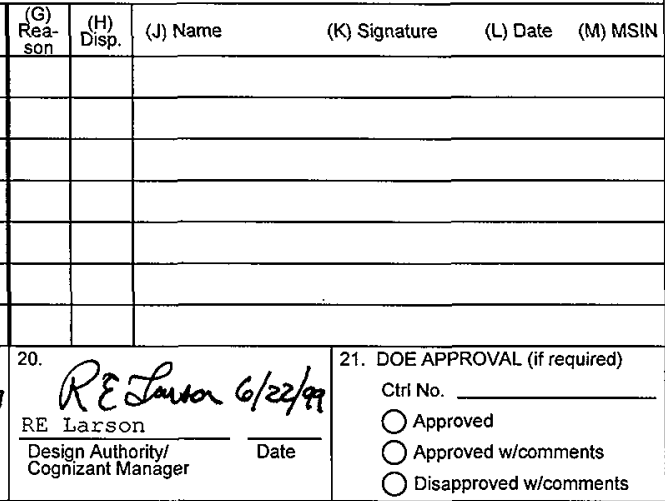




\section{1-SY-101 DACS Instrument Problem Screen (SCR 448) Acceptance Test Procedure}

A. M. Ermi

COGEMA Engineering Corporation, P.O. Box 840

Richland, WA 99352

U.S. Department of Energy Contract DE-AC06-96RL13200

EDT/ECN: 140136

Org Code: $\$ 4100$

B\&R Code: EW3120072
UC: 2030

Charge Code: 102525 / BC20 HN920201

Total Pages: 24

Key Words: DACS, DATA ACQUISITION AND CONTROL SYSTEM, 241SY101, MIXER PUMP, ATP

Abstract: The operability of the 241-SY-101 Data Acquisition and Control System (DACS) to provide proper control and monitoring of the mitigation mixer pump and instrumentation installed in the 241-SY-101 underground storage tank utilizing the [INSTPROB] screen will be systematically evaluated by the performance of this procedure.

* Micron is a registered trademark of Micron Electronics, Inc. *Modicon \& Modbus Plus are registered trademarks of AEG Schneider Automation, Inc.

TRADEMARK DISCLAIMER. Reference here in to any specific commercial product, process, or service by trade name, trademark, manufacturer, or otherwise, does not necessarily constitute or imply its endorsement, recommendation, or favoring by the United States Government or any agency thereof or its contractors or subcontractors.

Printed in the United States of America. To obtain copies of this document, contact: Document Control Services, P.O. Box 950, Mailstop H6-08, Richland WA 99352, Phone (509) 372-2420; Fax (509) 376-4989.
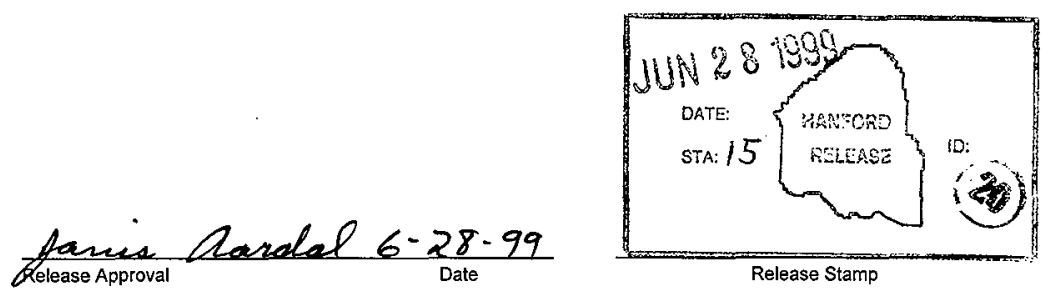

Release Stamp 


\title{
241-SY-101 DACS INSTRUMENT PROBLEM SCREEN (SCR 448) ACCEPTANCE TEST PROCEDURE
}

\author{
HNF - 4687 \\ Revision 0
}

Prepared By:

A. C. Zuehlke

PLCs Plus, Richland, WA for

Lockheed-Martin Hanford Company, Richland, WA

June 1999 


\section{TABLE OF CONTENTS}

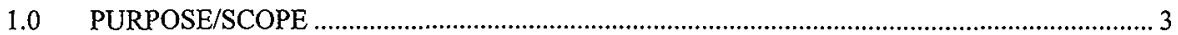

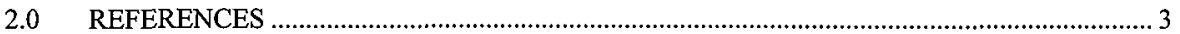

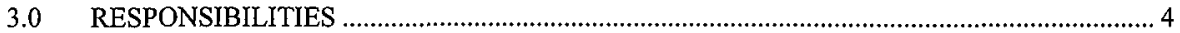

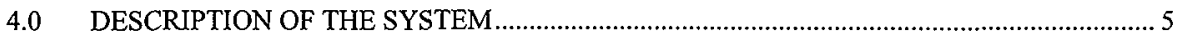

5.0 TEST CONDITIONS AND EQUIPMENT REQUIRED ……….......................................

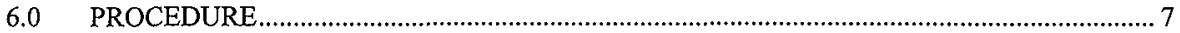

6.1. Display Screen and Screen Security Checks ……........................................................ 7

6.2. "ENABLE ALL" Button Checks............................................................................. 10

6.3. Screen Checks for [INSTPROB] Screen ……......................................................... 12

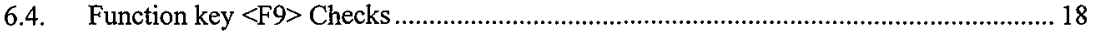

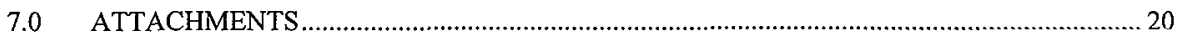

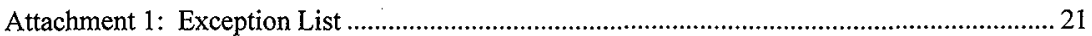

Attachment 2: Measurement and Test Equipment Record Sheet ............................................... 22

Attachment 3: Final Procedure Acceptance Sheet....................................................................... 23 


\subsection{PURPOSE/SCOPE}

The operability of the 241-SY-101 Data Acquisition and Control System (DACS) computer system to provide proper control and monitoring of the mitigation mixer pump and instrumentation installed in the 241-SY-101 underground storage tank utilizing the [INSTPROB] screen, will be systematically evaluated by the performance of this procedure.

The [INSTPROB] screen will be verified to provide:

- Adequate operator display and enabling/disabling of instrument problem alarms.

- Proper alarm notification and display.

- Proper interface with the Programmable Logic Controller (PLC) for system control.

- Proper system security, including passwords and levels of authorization for screen use.

The "ENABLE ALL" button on the [TAGSTAT] and [INSTPROB] screens will be tested to function properly.

The "Enable All" function of the $<$ F9 $>$ key will be tested.

Testing will be performed in the DACS Development Lab, located in the $306 \mathrm{E}$ building in the 300 Area of the Hanford site. Instrumentation input signals will be simulated in order to verify the proper functioning of the screen software.

\subsection{REFERENCES}

2.1. HNF-1516, "Thermocouple Module Halt Failure Acceptance Test Procedure For Tank 241-SY-101 DACS-1", Revision 0

2.2. HNF-2989, "241-SY-101 Data Acquisition and Control System (DACS) Operator Interface Upgrade Acceptance Test Procedure", Revision 0

2.3. HNF-SD-WM-SDD-045, "System Design Description for the SY-101 Hydrogen Mitigation Test Project Data Acquisition and Control System (DACS-1)", Revision 4-A

2.4. WHC-SD-WM-ATP-046, "101-SY Mitigation Testing Acceptance Test Procedure", Revision 0

2.5. WHC-SD-WM-ATP-058, "101-SY Post Pump-Installation Acceptance Test Procedure", Revision 1

2.6. WHC-SD-WM-ATP-061, "MIT Acceptance Test Procedure", Revision 0

\begin{tabular}{|c|c|c|}
\hline PROCEDURE NUMBER: & Revision Number: & Page Number: \\
HNF-4687 & 0 & 3 of 23 \\
\hline
\end{tabular}


2.7. WHC-SD-WM-ATP-062, "Phase B Mitigation Testing Software Acceptance Test Procedure", Revision 0

2.8. WHC-SD-WM-ATP-069, "Acceptance Test Procedure For Tank Bottom Thermocouples On Tank 241-SY-101", Revision 2

2.9. WHC-SD-WM-ATP-070, "101-SY Post Phase B Acceptance Test Procedure", Revision 0-A

2.10. WHC-SD-WM-ATP-082, "DACS Upgrade Acceptance Test Procedure”, Revision 0

2.11. WHC-SD-WM-ATP-098, "GMS/DACS Interface Acceptance Test Procedure", Revision 0

2.12. WHC-SD-WM-ATP-107, "MIT Upgrade Acceptance Test Procedure", Revision 1

2.13. WHC-SD-WM-ATP-128, "Operator Coil Monitoring Acceptance Test Procedure", Revision 0

\subsection{RESPONSIBILITIES}

The following personnel will be required for the performance of this procedure:

- DACS Cognizant Engineer: The individual assigned direct responsibility for the performance, preparation, and adequacy of the test.

- Test Director: The engineer assigned shift responsibility for performance of the test.

- Test Engineer: The engineer assigned to assist and relieve the Test Director during the performance of the test.

Only personnel designated by the DACS Cognizant Engineer are allowed to direct testing per this procedure, and perform equipment operating and control functions.

One engineer acting as either a Test Director or as a Test Engineer is required to be present during testing.

If, during testing, any indicated parameter or control function is not correct or appears to be malfunctioning, then the engineer conducting this test shall make a determination as to the feasibility of continuing testing. Since actual DACS and mitigation mixer pump operation will not occur during this test, there should be no safety impact to continuing the test and completing corrective actions later. A. record of all noted deficiencies will be kept on Attachment 1, "Exception List".

\begin{tabular}{|c|c|c|}
\hline PROCEDURE NUMBER: & Revision Number: & Page Number: \\
HNF-4687 & 0 & 4 of 23 \\
\hline
\end{tabular}




\section{DACS INSTRUMENT PROBLEM SCREEN ACCEPTANCE TEST PROCEDURE}

At the completion of all testing, approval of all data collected and system performance shall be documented on Attachment 3, "Final Procedure Acceptance Sheet".

Any required changes to this procedure shall be approved by the DACS Cognizant Engineer, or a designated representative, and may be made as "pen-and-ink" changes in all official and working copies of the procedure. An entry shall be made in the official Test Log fully describing the change or changes and the reason for the change(s). If required because of the nature of the change, an $\mathrm{ECN}$, documenting the change or changes, shall be initiated by the DACS Cognizant Engineer and approved per administrative requirements, however testing is not required to be stopped during the ECN initiation and approval process.

\subsection{DESCRIPTION OF THE SYSTEM}

The DACS computer system, to be tested per this procedure, consists of three Micron $400 \mathrm{Mhz}$ Personal Computers (PCs), networked together via a 10-Base-T network and connected to a Modicon Model 984 PLC via a Modbus Plus network. The three PCs are programmed with Intellution HMI software, and provide full operator interface for the control and monitoring of the 241-SY-101 instrumentation and mitigation mixer pump, as currently "mocked up" in the Building 306E DACS Development Lab.

The portions of the system to be tested include:

- The [INSTPROB] screen and screen controls.

- Other system screens that have dynamic screen links to the [INSTPROB] screen.

- System security implementation and password control, as related to the [INSTPROB] screen.

- The "ENABLE ALL" button on the [TAGSTAT] and [INSTPROB] screens.

- The "Enable All" function of the $<$ F9> key to enable all disabled Instrument Problem and other system alarms on the [TAGSTAT] and [NNSTPROB] screens.

\subsection{TEST CONDITIONS AND EQUIPMENT REQUIRED}

5.1. Jumpers and Lifted Leads

Not applicable to this procedure.

\begin{tabular}{|c|c|c|}
\hline PROCEDURE NUMBER: & Revision Number: & Page Number: \\
HNF-4687 & 0 & 5 of 23 \\
\hline
\end{tabular}


5.2. Unexpected Alarms

If unexpected Building $306 \mathrm{E}$ facility equipment alarms or abnormal indications are received during testing, testing evolutions shall be immediately suspended and actions, as prescribed in approved Building 306E facility Alarm Response and Emergency Procedures, shall be taken by responsible facility personnel to place the equipment/facility in a safe, stable condition. When the reason for the unexpected condition is understood and resolved, then testing activities may be resumed after permission to do so is received from the cognizant 306E Building Administrator.

5.3. Prior to initiation of testing, and at the start of each shift during testing, test personnel shall be briefed on the scope of testing to be conducted during the shift. The briefing shall include any equipment to be operated or controlled during the shift. Additionally, a discussion of work in the facility that could affect testing shall also be held between the cognizant 306E Building Administrator and the acting Test Director in charge of the test to be conducted.

5.4. Prior to initiation of testing, the following items shall be verified:

5.4.1. The DACS computers, lab PLCs and Input/Output (I/O) modules and controls are installed and ready for testing.

Test Director

1 Date

5.4.2. The latest version of software and programming to be tested has been loaded on to the DACS lab computers and PLC.

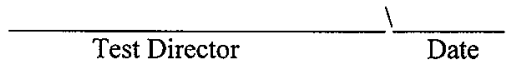

5.5. Prior to initiation of testing, the following equipment shall be available for use:

None

5.6. Attachment 2, "Measurement and Test Equipment Record Sheet", is included in Section 7.0 for recording data associated with $M$ \& TE used during the performance of this procedure.

5.7. All M \& TE used for testing shall be in current calibration and shall have documentation certifying that the calibration is traceable to a national standard. 


\subsection{PROCEDURE}

\section{NOTE:}

Sections and steps in this procedure should be performed in the order presented to maintain the continuity of the testing sequence. The order of the performance of sections and/or steps may be varied however, at the discretion of the Test Director.

\subsection{Display Screen and Screen Security Checks}

6.1.1. If any discrepancy is noted during testing, then record a description of the condition in Attachment 1 .

6.1.1.1. For each discrepancy recorded, enter an identifying number in the "EXCEPTION NUMBER" Column of Attachment 1.

6.1.1.2. Reproduce Attachment 1 as needed, and attach the additional pages to this procedure, to record all discrepancies noted during testing.

\section{NOTES:}

In this procedure the verb "select" means that the test engineer should position the mouse pointer over the button, icon, or other item on the computer display screen and "click" the left mouse button.

"OPS" is the name and password for operator level access to the DACS for testing purposes.

"SUPER" is the name and password for supervisor level access to the DACS for testing purposes.

" $\mathrm{A}$ " is the name, and there is no password for administrator/developer level access to the DACS for testing purposes.

"TRAINER" is the name, and "TRAIN" is the password for training level access to the DACS for testing purposes.

6.1.2. Start up the Intellution FIX32 "VIEW" program on all DACS computers to be tested, and verify that the [WELCOME] screen is displayed at all stations. 


\section{NOTE:}

Steps 6.1.3 through 6.1.12 are to be performed at station 5.

6.1.3. From the [WELCOME] screen, select the "INSTPROB" button, and verify that the [INSTPROB] screen is displayed.

6.1.4. On the [INSTPROB] screen, select the "MAP" button, and verify that the [MAP] screen is displayed.

6.1.5. From the [MAP] screen, select the "INSTPROB" button, and verify that the [INSTPROB] screen is displayed.

6.1.6. On the [INSTPROB] screen, select the "MAP" button, and verify that the [MAP] screen is displayed.

6.1.7. Access the [MININ] screen, select the "INSTPROB" button, and verify that the [INSTPROB] screen is displayed.

6.1.8. On the [INSTPROB] screen, select the "MININ" button, and verify that the [MININ] screen is displayed.

6.1.9. Access the [TAGSTAT] screen, select the "INSTPROB" button, and verify that the [INSTPROB] screen is displayed.

6.1.10. On the [INSTPROB] screen, select the "TAGSTAT" button, and verify that the [TAGSTAT] screen is displayed.

6.1.11. Access the [ABRTENAB] screen, select the "INSTPROB" button, and verify that the [INSTPROB] screen is displayed.

6.1.12. On the [INSTPROB] screen, select the "ABRTENAB" button, and verify that the [ABRTENAB] screen is displayed.

6.1.13. At station 6, access the [INSTPROB] screen and attempt to disable any instrument problem alarm.

6.1.14. Verify that no screen changes occur.

6.1.15. Attempt to place any tag in Manual.

6.1.16. Verify that no screen changes occur.

\begin{tabular}{|c|c|c|}
\hline PROCEDURE NUMBER: & Revision Number: & Page Number: \\
HNF-4687 & 0 & 8 of 23 \\
\hline
\end{tabular}


6.1.17. At station 6, login as "OPS".

6.1.18. Attempt to disable any instrument problem alarm.

6.1.19. Verify that the alarm status shows that the tag alarm is in a disabled condition.

6.1.20. Attempt to place any tag in Manual.

6.1.21. Verify that no screen changes occur.

6.1.22. Enable the alarm for the tag that was disabled in Step 6.1.18.

6.1.23. Login as "SUPER".

6.1.24. Attempt to disable any instrument problem alarm.

6.1.25. Verify that the alarm status shows that the tag alarm is in a disabled condition.

6.1.26. Attempt to place any tag in Manual.

6.1.27. Verify that no screen changes occur.

6.1.28. Enable the alarm for the tag that was disabled in Step 6.1.24.

6.1.29. Login as "A".

6.1.30. Attempt to disable any instrument problem alarm.

6.1.31. Verify that the alarm status shows that the tag alarm is in a disabled condition.

6.1.32. Attempt to place any tag in Manual.

6.1.33. Verify that the tag status shows that the tag is in Manual.

6.1.34. Enable the alarm for the tag that was disabled in Step 6.1.30.

6.1.35. Place the tag in Auto that was placed in Manual in Step 6.1.32.

6.1.36. Login as "TRAINER".

6.1.37. Attempt to disable any instrument problem alarm.

\begin{tabular}{|c|c|c|}
\hline PROCEDURE NUMBER: & Revision Number: & Page Number: \\
HNF-4687 & 0 & 9 of 23 \\
\hline
\end{tabular}


6.1.38. Verify that the alarm status shows that the tag alarm is in a disabled condition.

6.1.39. Attempt to place any tag in Manual.

6.1.40. Verify that the tag status shows that the tag is in Manual.

6.1.41. Enable the alarm for the tag that was disabled in Step 6.1.37.

6.1.42. Place the tag in Auto that was placed in Manual in Step 6.1.39.

\subsubsection{Login as "OPS".}

Testing as directed by this procedure section has been completed, and discrepancies, if any, have been listed on Attachment 1, Exception List.

Test Engineer:

Date:

\section{2. "ENABLE ALL" Button Checks}

6.2.1. If any discrepancy is noted during testing, then record a description of the condition in Attachment 1.

6.2.1.1. For each discrepancy recorded, enter an identifying number in the "EXCEPTION NUMBER" Column of Attachment 1.

6.2.1.2. Reproduce Attachment 1 as needed, and attach the additional pages to this procedure, to record all discrepancies noted during testing.

\section{NOTES:}

The "ENABLE ALL" button is displayed only on the [TAGSTAT] and [INSTPROB] screens when an OPS level password or higher has been properly entered.

On the [TAGSTAT] and [INSTPROB] screens, if a WHITE "D" or " $E$ " is displayed inside a WHITE box preceding a tagname, the alarm status of that tag cannot be changed.

6.2.2. At station 8, login as "OPS".

6.2.3. At station 8, access the [TAGSTAT] screen, verify that the "ENABLE ALL" button is visible on the screen, and disable any 10 tags.

PROCEDURE NUMBER:

HNF-4687
Revision Number:

(

Page Number:

10 of 23 
6.2.4. At station 8, access the [INSTPROB] screen, verify that the "ENABLE ALL" button is visible on the screen, and disable any 10 tags.

6.2.5. At station 8, login as "PUBLIC".

6.2.6. At station 8, access the [INSTPROB] screen, verify that the "ENABLE ALL" button is not visible, and that the message "REQUIRES OPERATOR PASSWORD" is visible.

6.2.7. At station 8, access the [TAGSTAT] screen, verify that the "ENABLE ALL" button is not visible, and that the message "REQUIRES OPERATOR PASSWORD" is visible.

6.2.8. At station 8, login as "OPS".

6.2.9. At station 8, access the [TAGSTAT] screen, verify that the "ENABLE ALL" button is visible, and that the message "REQUIRES OPERATOR PASSWORD" is no longer visible.

6.2.10. At station 8, access the [INSTPROB] screen, verify that the "ENABLE ALL" button is visible, and that the message "REQUIRES OPERATOR PASSWORD" is no longer visible.

6.2.11. At station 8, access the [TAGSTAT] screen, press the "ENABLE ALL" button and verify that a message box with the message "Enabling All Alarms .... Please Wait" is displayed.

6.2.12. After a time delay, verify that the message box with the message "Enabling All Alarms .... Please Wait" is no longer displayed and that the 10 alarms that were disabled in Step 6.2.3 have been enabled.

6.2.13. At station 8, access the [INSTPROB] screen, press the "ENABLE ALL" button and verify that a message box with the message "Enabling All Alarms .... Please Wait" is displayed.

6.2.14. After a time delay, verify that the message box with the message "Enabling All Alarms .... Please Wait" is no longer displayed and that the 10 alarms that were disabled in Step 6.2.4 have been enabled.

Testing as directed by this procedure section has been completed, and discrepancies, if any, have been listed on Attachment 1, Exception List.

Test Engineer: Date:

\begin{tabular}{|c|c|c}
\hline PROCEDURE NUMBER: & Revision Number: & Page Number: \\
HNF-4687 & 0 & 11 of 23 \\
\hline
\end{tabular}




\subsection{Screen Checks for [INSTPROB] Screen}

6.3.1. If any discrepancy is noted during testing, then record a description of the condition in Attachment 1.

6.3.1.1. For each discrepancy recorded, enter an identifying number in the "EXCEPTION NUMBER" Column of Attachment 1.

6.3.1.2. Reproduce Attachment $l$ as needed, and attach the additional pages to this procedure, to record all discrepancies noted during testing.

6.3.2. At station 5, login as "SUPER".

6.3.3. At station 5, access the [INSTPROB] screen.

6.3.4. Verify that the "ENABLE ALL" button is visible.

6.3.5. Perform the following for each tagname listed below:

\begin{tabular}{|c|c|c|c|c|c|}
\hline & FT-INST & • & FZE50001 & • & FZE50002 \\
\hline & FZE50003 & • & GC1-INST & $\bullet$ & GC2-INST \\
\hline & GC3-INST & $\bullet$ & LZR01A & • & LZR01C \\
\hline • & NZR05A01 & • & NZR17B01 & $\bullet$ & NZTJSY06 \\
\hline 8 & NZTKSY06 & • & PHO-INST & $\bullet$ & PZR12A01 \\
\hline$\theta^{\circ}$ & PZR17B04 & $\bullet$ & PZR17C01 & $\bullet$ & PZTNO110 \\
\hline & PZTNO111 & - & TZR12A01 & $\bullet$ & TZR12A02 \\
\hline & TZR17B01 & $\bullet$ & TZR17B02 & - & TZR17B03 \\
\hline & TZR17B04 & • & TZR17B05 & • & TZR17B06 \\
\hline & TZR17B07 & $\bullet$ & TZR17B08 & $\bullet$ & TZRI7B09 \\
\hline & TZR17B10 & • & TZR17B11 & - & TZR17B12 \\
\hline & TZR17B 13 & $\bullet$ & TZR17B14 & $\bullet$ & TZR17B 15 \\
\hline & TZR17B16 & • & TZR17B17 & • & TZR17B18 \\
\hline & TZR17B19 & • & TZR17B20 & $\bullet$ & TZR17B21 \\
\hline & TZR17B22 & 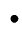 & TZR17C01 & $\bullet$ & TZR17C02 \\
\hline & TZR17C03 & $\bullet$ & TZR17C04 & $\bullet$ & TZR17C05 \\
\hline & TZR17C06 & • & TZR17C07 & $\bullet$ & TZR17C08 \\
\hline & TZR17C09 & . & TZR17C10 & • & TZR17C11 \\
\hline & TZR17C12 & • & TZR17C13 & • & TZR17C14 \\
\hline & TZR17C15 & $\bullet$ & TZR17C16 & $\bullet$ & TZR17C17 \\
\hline . & TZR17C18 & $\bullet$ & TZR 17C20 & $\bullet$ & TZR17C21 \\
\hline . & WZR1BA01 & • & WZR $1 B A 02$ & - & WZR1BA03 \\
\hline . & WZR12A01 & $\bullet$ & WZR $12 A 02$ & - & WZR $12 A 03$ \\
\hline
\end{tabular}

\begin{tabular}{c|c|c}
\hline PROCEDURE NUMBER: & Revision Number: & Page Number: \\
HNF-4687 & 0 & 12 of 23 \\
\hline
\end{tabular}


$\begin{array}{llll}\text { - } & \text { WZR12A04 } & \text { ZZMPE142 } & \text { WZR17C01 }\end{array}$

6.3.5.1. Select the WHITE "E" in the GRAY box preceding a listed tagname.

6.3.5.2. Verify that a WHITE " $D$ " in a RED box is now visible preceding the tagname and the WHITE " $E$ " in the GRAY box is no longer visible.

6.3.5.3. Select the WHITE " $D$ " in the RED box for the listed tagname.

6.3.5.4. Verify that a WHITE "E" in a GREY box is now visible preceding the tagname and the WHITE " $D$ " in the RED box is no longer visible.

\section{NOTE:}

The instruments for tags TZR17C19 and TZR17C22 are Out-of-Service. The "ENABLE"/"DISABLE" and "AUTO"/"MANUAL" functions for these tags are not functional.

6.3.6. Perform the following for each tagname listed below:

- $\quad$ TZR17C19 • TZR17C22

6.3.6.1. Select the WHITE "D" in the GRAY box preceding a listed tagname.

6.3.6.2. Verify that a RED message box is displayed with the message "NOTE: TOGGLE FEATURE NOT AVAILABLE FOR THIS TAG".

6.3.6.3. After a time delay, verify that the RED message box is no longer displayed and that no other screen changes occur.

6.3.7. At the computer which is running the Modsoft software, access the "IP_17B", "IP_17C", and "IP_OTHRS" templates.

6.3.8. At station 5, login as "A".

6.3.9. Perform the following for each tagname listed below:

\begin{tabular}{|c|c|c|c|c|}
\hline NST & & FZE50001 & - & FZE50002 \\
\hline & & GC1-INST & - & GC2-INST \\
\hline & - & LZR01A & - & $\mathrm{LZ}$ \\
\hline & $\bullet$ & NZR17B01 & - & \\
\hline
\end{tabular}




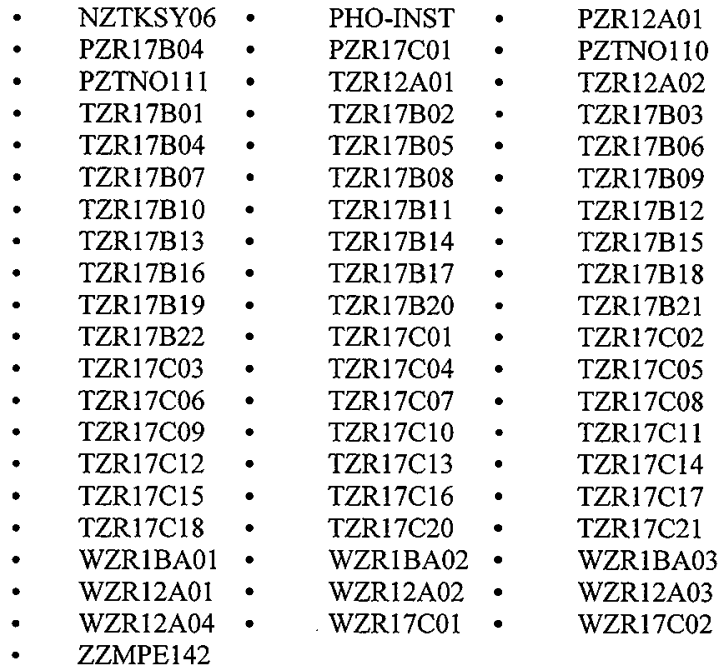

6.3.9.1. Verify that a " 0 " is displayed in the column to the far right of the listed tag.

6.3.9.2. Select the "0" and verify that no automatic screen actions occur, other than highlighting the " 0 ".

6.3.9.3. Press the $<$ F2 $>$ key and verify that the associated "Tag Details" screen is displayed.

6.3.9.4. In the "Current State" block of the displayed tag details screen, verify "Alarm Status:" is "OK".

6.3.9.5. Close the "Tag Details" screen.

6.3.9.6. In Modsoft, disable the PLC tag associated with the listed tag.

6.3.9.7. Force the PLC value for the listed tag to "1".

6.3.9.8. Verify that the instrument problem alarm associated with the listed tag is actuated.

\begin{tabular}{|c|c|r|}
\hline PROCEDURE NUMBER: & Revision Number: & Page Number: \\
HNF-4687 & 0 & 14 of 23 \\
\hline
\end{tabular}


6.3.9.9. Acknowledge the alarm.

6.3.9.10. Verify that a " 1 " is displayed in the column to the far right of the listed tag.

6.3.9.11. Verify that the tagname and the "1" are now displayed in YELLOW letters.

6.3.9.12. Disable the alarm for the listed tag.

6.3.9.13. Verify that the tagname and the "1" are no longer displayed in YELLOW letters.

6.3.9.14. Verify that the alarm is no longer displayed for the listed tag in the "ALARM SUMMARY" portion of the [INSTPROB] screen.

6.3.9.15. Verify that a " 1 " is still displayed in the column to the far right of the listed tag.

6.3.9.16. Select the " 1 " and press the $<F 2>$ key.

6.3.9.17. Verify that the associated "Tag Details" screen is displayed.

6.3.9.18. In the "Current State" block of the displayed tag details screen, verify "Alarm Status:" is "DSAB".

6.3.9.19. Close the "Tag Details" screen.

6.3.9.20. Force the PLC value for the listed tag to " 0 ".

6.3.9.21. Verify that a " 0 " is now displayed in the column to the far right of the listed tag.

6.3.9.22. In Modsoft, enable the PLC tag associated with the listed tag.

6.3.9.23. Enable the alarm for the listed tag.

6.3.9.24. Verify that all of the screen indications for the listed tag have returned to normal.

6.3.9.25. Display the "Tag Details" screen for the listed tag and verify in the "Current State" block that "Alarm Status:" is "OK".

\begin{tabular}{|c|c|c|}
\hline PROCEDURE NUMBER: & Revision Number: & Page Number: \\
HNF-4687 & 0 & 15 of 23 \\
\hline
\end{tabular}




\subsubsection{Close the "Tag Details" screen.}

6.3.10. At station 5, login as "TRAINER".

6.3.11. Perform the following for each tagname listed below:

\begin{tabular}{|c|c|c|c|c|}
\hline FT-INST & - & FZE50001 & $\bullet$ & FZE50002 \\
\hline FZE50003 & $\bullet$ & GC1-INST & - & GC2-INST \\
\hline GC3-INST & - & LZR01A & 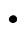 & LZR01C \\
\hline NZR05A01 & - & NZR17B01 & - & NZTJSY06 \\
\hline NZTKSY06 & - & PHO-INST & - & PZR12A01 \\
\hline PZR17B04 & - & PZR17C01 & - & PZTNO110 \\
\hline PZTNO111 & - & TZR12A01 & - & TZR12A02 \\
\hline TZR17B01 & - & TZR17B02 & - & TZR17B03 \\
\hline TZR17B04 & - & TZR17B05 & - & TZR17B06 \\
\hline TZR17B07 & - & TZR17B08 & - & TZR17B09 \\
\hline TZR17B10 & $\bullet$ & TZR17B11 & - & TZR17B12 \\
\hline TZR17B13 & - & TZR17B14 & - & TZR17B15 \\
\hline TZR17B16 & - & TZR17B17 & - & TZR17B18 \\
\hline TZR17B19 & - & TZR17B20 & 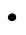 & TZR17B21 \\
\hline TZR17B22 & - & TZR17C01 & - & TZR17C02 \\
\hline TZR17C03 & - & TZR17C04 & - & TZR17C05 \\
\hline TZR17C06 & - & TZR17C07 & - & TZR17C08 \\
\hline TZR17C09 & $\bullet$ & TZR17C10 & - & TZR17C11 \\
\hline TZR17C12 & - & TZR17C13 & - & TZR17C14 \\
\hline TZR17C15 & $\bullet$ & TZR17C16 & - & TZR17C17 \\
\hline TZR17C18 & - & TZR17C20 & - & TZR17C21 \\
\hline WZR1BA01 & - & WZR1BA02 & - & WZR1BA03 \\
\hline WZR12A01 & - & WZR12A02 & - & WZR12A03 \\
\hline WZR12A04 & - & WZR17C01 & - & WZR17C02 \\
\hline
\end{tabular}

6.3.11.1. Access the "Tag Details" screen and verify, in the "Current State" block, that "Block Status:" is "AUTO".

6.3.11.2. Close the "Tag Details" screen.

6.3.11.3. Select the WHITE " $A$ " in the GRAY box to the right of the listed tag.

6.3.11.4. Verify that a BLACK " $M$ " in a YELLOW box is displayed and that the WHITE " $A$ " in the GRAY box is no longer displayed.

\begin{tabular}{|c|c|c|}
\hline PROCEDURE NUMBER: & Revision Number: & Page Number: \\
HNF-4687 & 0 & 16 of 23 \\
\hline
\end{tabular}


6.3.11.5. Access the "Tag Details" screen and verify, in the "Current State" block, that "Block Status:" is "MANL".

6.3.11.6. Close the "Tag Details" screen.

6.3.11.7. Double-click the " 0 " value to the far right of the listed tag and verify that a "Push Button Entry" pop-up screen is displayed.

6.3.11.8. Select the "Cancel" push button and verify that the "Push Button Entry" pop-up screen is no longer displayed.

6.3.11.9. Double-click the " 0 " value to the far right of the listed tag and verify that a "Push Button Entry" pop-up screen is displayed.

6.3.11.10. Select the " 1 " push button and verify:

- The pop-up screen is no longer displayed.

- The instrument problem alarm associated with the listed tag is actuated.

- A " 1 " is displayed in the column to the far right of the listed tag.

- The tagname and the " 1 " are now displayed in YELLOW letters.

6.3.11.11. Acknowledge the alarm.

6.3.11.12. Double-click the " 1 " value to the far right of the listed tag and verify that a "Push Button Entry" pop-up screen is displayed.

6.3.11.13. Select the "0" push button and verify:

- The pop-up screen is no longer displayed.

- The instrument problem alarm associated with the listed tag is clear.

- A "0" is displayed in the column to the far right of the listed tag.

- The tagname and the "0" are not displayed in YELLOW letters.

6.3.11.14. Select the BLACK "M" in the YELLOW box to the right of the listed tag.

\begin{tabular}{|c|c|c|}
\hline PROCEDURE NUMBER: & Revision Number: & Page Number: \\
HNF-4687 & 0 & 17 of 23 \\
\hline
\end{tabular}


6.3.11.15. Verify that a WHITE " $\mathrm{A}$ " in a GRAY box is displayed and that the BLACK " $M$ " in the YELLOW box is no longer displayed.

6.3.11.16. Access the "Tag Details" screen and verify, in the "Current State" block, that "Block Status:" is "AUTO".

6.3.11.17. Close the "Tag Details" screen.

Testing as directed by this procedure section has been completed, and discrepancies, if any, have been listed on Attachment 1, Exception List.

Test Engineer: Date:

\subsection{Function key $<$ F9 $>$ Checks}

6.4.1. If any discrepancy is noted during testing, then record a description of the condition in Attachment 1.

6.4.1.1. For each discrepancy recorded, enter an identifying number in the "EXCEPTION NUMBER" Column of Attachment 1.

6.4.1.2. Reproduce Attachment 1 as needed, and attach the additional pages to this procedure, to record all discrepancies noted during testing.

6.4.2. At station 6, login as "OPS".

6.4.3. At station 6, access the [TAGSTAT] screen, verify that the "ENABLE ALL" button is visible on the screen, and disable any 10 tags.

6.4.4. At station 8, access the [INSTPROB] screen, verify that the "ENABLE ALL" button is visible on the screen, and disable any 10 tags.

6.4.5. At station 6, login as "PUBLIC".

6.4.6. At station 6, press the <F9> key and verify that a RED "WARNING:" pop-up screen with the message "INSUFFICIENT SECURITY LEVEL TO ENABLE ALARMS" is displayed.

6.4.7. At station 6, login as "OPS". 
6.4.8. At station 6, press the $\angle \mathrm{F} 9>$ key and verify that a YELLOW pop-up message box is displayed with the message "Are You Sure That You Want to Enable All [TAGSTAT] High/Low Alarms and All [INSTPROB] Instrument Problem Alarms?".

6.4.9. Select the "CANCEL" button on the pop-up message box, verify that the message box is no longer displayed, and that no other screen changes have occurred.

6.4.10. At station 6, press the $\angle \mathrm{F} 9>$ key and verify that a YELLOW pop-up message box is displayed with the message "Are You Sure That You Want to Enable All [TAGSTAT] High/Low Alarms and All [INSTPROB] Instrument Problem Alarms?".

6.4.11. Select the "YES" button on the pop-up message box and verify that a new YELLOW pop-up message box is displayed with the message "Enabling All Alarms .... Please Wait" is displayed.

6.4.12. After a time delay, verify that no message boxes are displayed and that all of the alarms that were disabled in Steps 6.4.3 and 6.4.4 are enabled.

Testing as directed by this procedure section has been completed, and discrepancies, if any, have been listed on Attachment 1, Exception List.

Test Engineer: Date: 


\subsection{ATTACHMENTS}

7.1. Attachment 1, "Exception List"

7.2. Attachment 2, "Measurement and Test Equipment Record Sheet"

7.3. Attachment 3, "Final Procedure Acceptance Sheet"

PROCEDURE NUMBER:

HNF-4687
Revision Number:

0 


\section{DACS INSTRUMENT PROBLEM SCREEN ACCEPTANCE TEST PROCEDURE}

(This page may be reproduced as necessary)

OTP Step Number:

OTP Exception Log Number:

Description of Exception:

Resolution of Exception:

\section{Resolution Approval:}

Test Director Signature:

Date:

Project Engineer Signature:

Date:

Quality Assurance Signature:

Date:

\section{Verification of Resolution Completion:}

Test Director Signature:

Date:

Quality Control Signature:

Date:

Attachment 1: Exception List

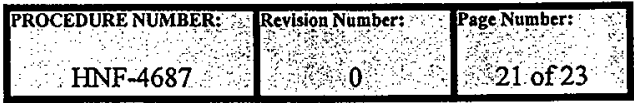




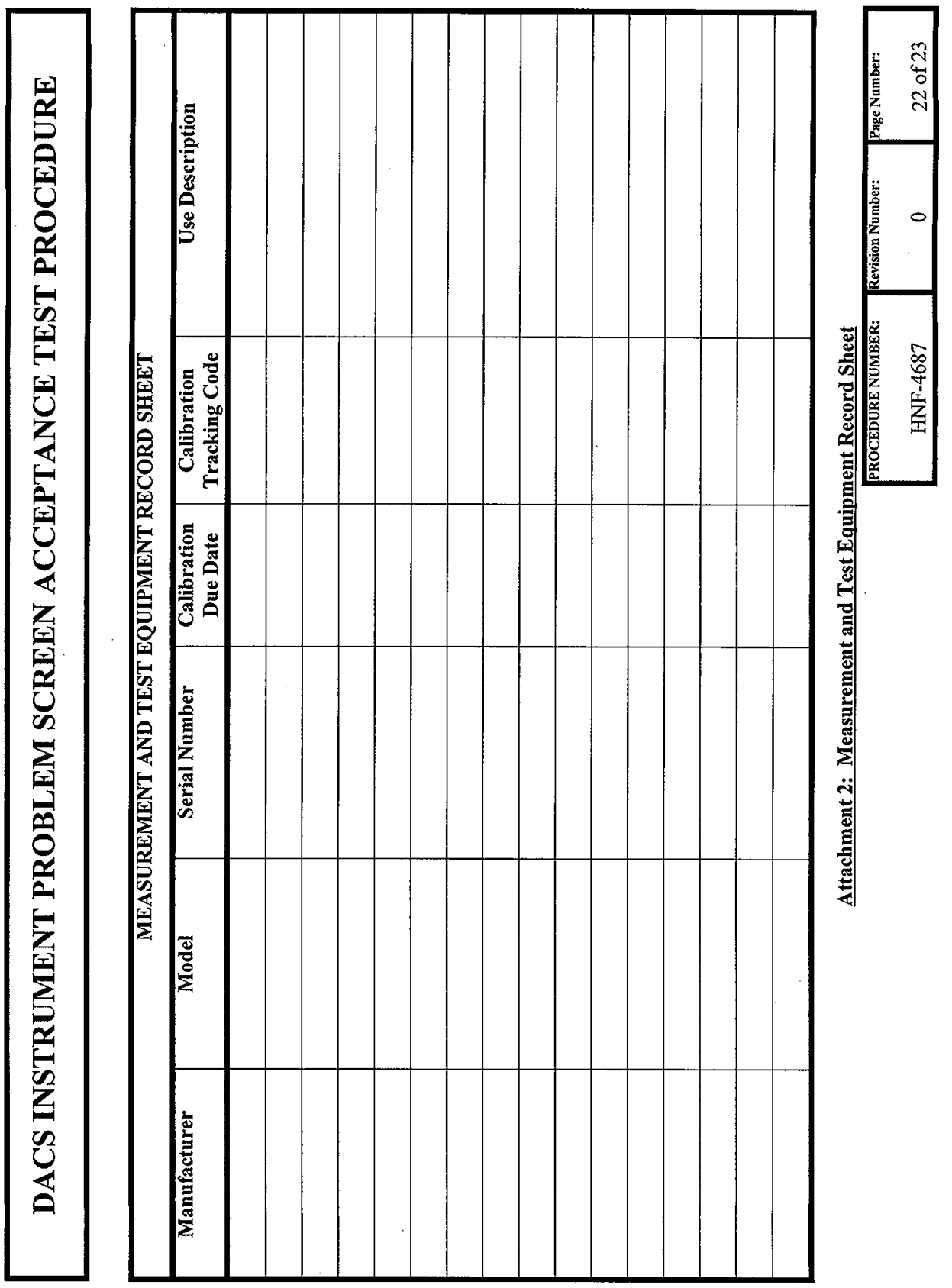


Completion of this procedure has demonstrated that:

- The [INSTPROB] screen is adequate for control and monitoring of DACS instrument problem alarms.

- System security, including passwords and levels of authorization for use with the [INSTPROB] screen, and the "ENABLE ALL" buttons, is satisfactory and adequate.

- The $<$ F9 $>$ key "ENABLE ALL" function for all system alarms is satisfactory.

A record of all noted deficiencies was kept on Attachment 1, Exception List, and all recorded exceptions have been resolved and the resolutions approved.

Approved by:

\begin{tabular}{ll}
${ } }$ & \\
\hline G. J. Gauck, Cognizant Engineer & Date
\end{tabular}

Attachment 3: Final Procedure Acceptance Sheet

PROCEDURE NUMBER:

HNF-4687
Revision Number:

0
Page Number:

23 of 23 


\section{DISTRIBUTION SHEET}

To

Distribution

Project Title $/$ Work Order

241-SY-101 DACS Instrument Problem Screen (SCR 448) Acceptance Test Procedure

M. H. Brown

A. M. Ermi (2)

G. J. Gauck

L. S. Krogsrud

D. C. Larsen

R. E. Larson

D. D. Tate

R. R. True

R. P. Tucker

Central Files

DOE/RL Reading Room

\section{Name}

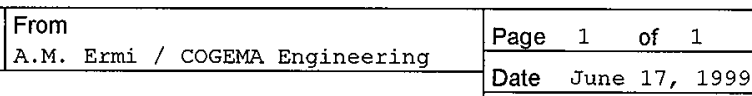

EDT No. 140136

ECN No, N/A

\begin{tabular}{|c|c|c|c|c|}
\hline MSIN & $\begin{array}{c}\text { Text } \\
\text { With All } \\
\text { Attach. }\end{array}$ & Text Only & $\begin{array}{l}\text { Attach. } \\
\text { Appendix } \\
\text { Only }\end{array}$ & $\begin{array}{c}\text { EDT/ECN } \\
\text { Only }\end{array}$ \\
\hline $\mathrm{T} 4-07$ & $\mathrm{X}$ & & & \\
\hline L6-37 & $\mathrm{x}$ & & & \\
\hline $\mathrm{T} 4-07$ & $\mathrm{x}$ & & & \\
\hline T4-07 & & & & $\mathrm{X}$ \\
\hline $\mathrm{T} 4-08$ & & & & $\mathrm{x}$ \\
\hline T 4-07 & & & & $\mathrm{x}$ \\
\hline L6-37 & & & & $\mathrm{x}$ \\
\hline $\mathrm{T} 4-07$ & & & & $\mathrm{x}$ \\
\hline T4-07 & & & & $x$ \\
\hline B1-07 & $x$ & & & \\
\hline $42-53$ & $x$ & & & \\
\hline & & & & \\
\hline
\end{tabular}

